\title{
Remote Delivery of ECE/CS Degree Education in China
}

\author{
Marcia Fischer, James E. Morris, Fu Li, Cynthia Brown, \\ Malgorzata Chrzanowska-Jeske, Agnes Hoffman, Xiangfu Zong \\ Portland State University/International Institute for Information \\ Science and Technology
}

\begin{abstract}
The Maseeh College of Engineering and Computer Science at Portland State University (PSU) has begun to deliver undergraduate ECE and CS courses to students in Shanghai, China at the International Institute for Information, Science \& Technology (IIIST) in an innovative experiment in international collaborative education. The courses consist of current lectures recorded in PSU classrooms, delivered with support materials by CD-ROM and Internet streaming, to students at the IIIST in Shanghai. All courses are taught in English by PSU faculty, with classroom assistance provided by local faculty drawn from Fudan and Shanghai JiaoTong Universities. IIIST provides classroom and administrative infrastructure, and collaborates with Fudan as well as Shanghai JiaoTong for most of the lower division non-technical program for the student. IIIST also provides instruction in English as a Second Language. Students who successfully complete the lower division program requirements can apply to become fully admitted to PSU at the junior year (upper division), and progress toward graduation from Portland State University. The program fosters faculty exchange between the two institutions, and presents computer science and engineering students enhanced opportunity for educational exchange and internships. An additional outcome of the program is that nearly all of the PSU ECE and CS undergraduate courses will be available online (or on CD) to students and other potential collaborators. The paper will provide details of the program's organization, administration and industry collaborations, and discuss challenges and successes of the program to date.
\end{abstract}

Introduction

The program began through a conversation on the topic of international education over a period of two days at conferences in Sweden and Germany in 2001. At the time, IIIST was running a BSCS program in cooperation with the University of Nebraska at Omaha (UNO), with the intent of providing a U.S. university degree, taught entirely in English, to prepare students for employment opportunities in the rapidly growing Shanghai high-tech market. IIIST was also interested in adding educational programs focused on VLSI design, which matched a strength in the PSU Department of Electrical and Computer Engineering (ECE.)

PSU and IIIST agreed that PSU would deliver undergraduate courses in ECE to IIIST students. When University of Nebraska at Omaha stopped offering CS courses in Shanghai, PSU began to offer CS courses there. ECE courses followed shortly thereafter. The initial plan was to also deliver graduate level courses at IIIIST, since both institutions were 
participants in a proposal to establish an international electronics packaging research consortium, to be supported by the degree program.

\section{IIIST}

The IIIST was constituted as a private university by Shanghai City. Most of the IIIST faculty are current Fudan faculty, with some recent appointments from the faculty ranks at Shanghai JiaoTong University. Originally named the Fudan IIIST, the Institute has since separated itself from the parent institution. The IIIST campus is located in the Pudong area of Shanghai. Facilities include classrooms, computer laboratories, faculty and staff offices, and dormitory facilities for students. ECE laboratory facilities are provided by Fudan University. IIIST currently enrolls about 200 freshmen, sophomores, juniors and seniors in Computer Science (CS) and about 70 ECE freshmen, sophomores, and juniors. The undergraduate students at IIIST are primarily full-time students, who are recruited directly from high school.

\section{PSU}

Portland State University has its roots in the G.I. Bill, and has since developed into a vibrant urban university, with a mission of service to the city. In recent years PSU has become the largest university in Oregon. The University has been nationally recognized for its innovative undergraduate curriculum, including its focus on service learning, community partnerships, internships and capstone experiences. The Maseeh College of Engineering and Computer Science, one of seven PSU schools and colleges, offers B.S., M.S., M.Eng., and Ph.D. degrees in a range of engineering and computer science disciplines. Students in engineering and computer science at PSU benefit from close involvement with local high-tech industry, including companies such as Intel, IDT, LSI Logic, Credence, Electro-Scientific Industries, InFocus, Maxim, Mentor Graphics, Flextronics, Tektronix, Triquint Semiconductor, Siltronic, and others.

PSU has a climate which supports international initiatives, led by President Dan Bernstine, who has identified internationalization of the campus and the curriculum as one of the priorities of the University.

Program overview

Students are selected to participate in the program at IIIST on the basis of the Chinese university entrance examination. The curriculum that students follow during the freshman and sophomore years is parallel to the PSU curriculum in EE, CpE, or CS. The lower division general education courses, mathematics, and science courses are taught in Chinese by Shanghai JiaoTong University. IIIST provides instruction in ESL for students who need additional instruction in English prior to taking the TOEFL (Test of English as a Foreign Language). During the freshman and sophomore years, students also take some PSU courses in CS or ECE, taught in English by PSU faculty, using distance education technology. Students in the lower division take these PSU courses through the PSU Quick Entry (non-admitted) registration process. 
At the end of the sophomore year, students may formally apply for admission to Portland State University, as transfer students. For admission to PSU, students must meet all regular PSU international admission requirements, including grade point average and TOEFL scores. The lower division courses and some upper division science or mathematics taken in Shanghai are accepted by PSU as transfer courses.

Once admitted to PSU, students progress through the PSU upper division courses in CS or ECE, delivered onsite at IIIST through distance delivery. PSU also delivers three upper division required general education courses.

Upon completion of all degree requirements, students apply for graduation from Portland State University. At the time of the writing of this paper, the first group of students has just applied for graduation from PSU with the B.S. degree.

PSU Course Delivery to Shanghai

All Computer Science and Electrical and Computer Engineering courses delivered to IIIST are taught by regular PSU faculty. The PSU courses are delivered each term as recorded lectures by the PSU faculty, delivered to IIIST via internet streaming. On-campus PSU courses are recorded as they are delivered live in a multi-media classroom in the PSU Distance Learning Center (DLC). The DLC is a professionally staffed facility equipped for remote lecture delivery, recording and post-processing. The post-processing phase for these courses adds lecture notes which are synchronized with the recorded lecture. IIIST supplies the receive-technology for the courses.

Students in Shanghai view the lectures in a multimedia classroom setting, in the presence of IIIST faculty "mentors", who provide classroom interaction, and respond to questions. The mentor may stop the playback of the lecture, and go over the problem or concept that has just been presented by the PSU faculty in more detail. The role of the mentor is similar to the role of a Teaching Assistant in a recitation section; however, the IIIST mentors are experienced faculty, usually from Fudan or JiaoTong Universities. These mentors are approved by the faculty at PSU. The PSU instructor is the instructor-of-record, and has ultimate responsibility for the course.

PSU has also offered some courses at IIIST via WEBCT. In summer 2004, two general education courses were piloted in Shanghai via WEB CT with assistance to the PSU faculty provided by the PSU Instructional Resource Center. For these courses, students at IIIST prepared and submitted assignments, and interacted directly with the PSU faculty over the internet in the same way as American students taking PSU WEBCT courses. Feedback from instructors and students has been encouraging that this delivery method may work well for future PSU distance education offerings at IIIST. The ECE department plans to use WebCT for instruction in their junior year laboratories. 
Organization of Program

Responsibility for contract compliance and financial issues rests with the PSU Business Affairs Office. The PSU Maseeh College of Engineering and Computer Science Dean's Office plays a central administrative coordinating role with the various offices and departments involved in program delivery.

The Departments of Computer Science and Electrical and Computer Engineering are responsible for the academic program, as well as for faculty exchange. The PSU Office of Academic Affairs has oversight of the academic program as with any approved program of study at PSU. Academic Departments providing University Studies Cluster Courses provide instruction and monitor academic quality for the Cluster Courses delivered in Shanghai. The PSU Office of International Affairs provides oversight of the program's relationship with the PSU Internationalization Initiative, advises on aspects pertaining to international relations, and will develop future student exchange programs in collaboration with the participating PSU academic departments.

The PSU Distance Delivery Center tapes the regular on-campus classes and provides postproduction services to prepare the courses for transmission to Shanghai. For the WEBCT classes, the PSU Instructional Resource Services office works with designated PSU faculty to prepare the WEBCT courses. The PSU Office of Admissions and Records is responsible for PSU course registration for the IIIST students, processing of the Quick Entry applications, processing of the regular PSU applications as received, and monitoring of academic standing toward the degree.

Physical Facilities and Laboratories

All physical facilities in Shanghai are the responsibility of IIIST. PSU faculty and administrators traveling to IIIST review facilities and equipment to ensure that they are appropriate for PSU instruction. IIIST provides classrooms, computers and software, internet connections, projection and other instructional equipment. PSU classroom facilities on campus and the Distance Learning Center provide support for the program.

Laboratories: Students at IIIST take required Electrical and Computer Engineering laboratory courses on the campus of Fudan University in Shanghai, through an agreement between IIIST and Fudan. PSU faculty have visited the lab facilities at Fudan, and report that the facilities and equipment are comparable to those at PSU. The equipment at Fudan is functionally the same as that at PSU, though the model numbers are different.

Student Services

PSU handles registration services for the University courses. PSU is also responsible for monitoring students' academic standing in their PSU courses. The PSU Office of Admissions and Records has set up an email address for admissions-related questions from the Shanghai students: shanghai_admit@pdx.edu. 
IIIST is responsible for providing student services that are specific to location, including housing, provision for food services, health services, etc. IIIST also organizes local internship placements for advanced students in the program. Academic advising is a responsibility of IIIST, based upon PSU guidelines. PSU faculty and staff advisors meet with IIIST personnel to ensure that PSU academic regulations, rules and policies_are carried out at IIIST. IIIST students taking PSU courses access their PSU records online, and communicate with student service personnel at PSU on email. Student questions are channeled to PSU through the IIIST administration, or received directly from students by email.

\section{Registration and Scheduling}

IIIST keeps detailed records of all students, all courses, assignments, and examinations graded in China. Administrators at IIIST sign up students for classes and send registrations to PSU for the PSU courses. Administrators at IIIST and JiaoTong register students for the Shanghai JiaoTong University classes. On the PSU campus, students are registered for sections of courses designated by a code specific to the IIIST Program in Shanghai.

Students progress through the program in a cohort fashion, though not all students perform equally well in all courses. Additionally, some students have withdrawn from the program, though to date retention in this program has been excellent. The failure of some students in some classes has created problems in registration and course scheduling. We have needed to increase the number of courses per year offered at IIIST in order to accommodate students who fall behind their initial cohort group.

A special IIIST registration schedule at PSU was set up in order to accommodate the academic schedule at IIIST. IIIST operates on 3 academic terms, which correspond roughly to the 3 quarters of the academic year at PSU. The IIIST terms start later than the PSU quarters, and contain different break schedules, to accommodate the differences in national holidays.

Typically a PSU faculty member will have his or her class session delivered in Shanghai several weeks after the same class session is delivered in Portland, and course examinations are also delivered later than they are in Portland. Communication with faculty mentors or students in Shanghai is therefore somewhat off schedule.

This off-sync schedule also causes challenges in registration/drops/etc, as everything must be processed on a different time schedule. PSU has hired a half-time admissions/registration specialist to process the unusual requirements of this program.

The off-sync schedule allows PSU to tape lecture sessions and add lecture notes during post-processing, before the course materials are streamed to Shanghai. 
Finances

The program operates at PSU on a self-support basis, by agreement with the PSU administration. A contractual Agreement administered at PSU by the Office of Business Affairs governs the program finances. IIIST pays an instructional fee to Portland State for the courses PSU delivers each academic year, as invoiced by PSU per the contract.

This contract instructional fee is based upon PSU in-state tuition rates, with consideration given for student scholarship support as well as for the facilities and infrastructure provided by IIIST. The net effect is that the fees that IIIST charges the students in China are competitive with other private Chinese institutions.

\section{$\underline{\text { Challenges Faced to Date }}$}

\section{English as a Second Language}

English language skills of the students have presented a significant challenge. Many of the students in the first group taking the TOEFL examination prior to applying for PSU admission did not pass the examination. The failure of these students to achieve a TOEFL score high enough for PSU admission meant that their admission to PSU at the junior level was delayed, causing a delay in their academic progress.

In recent months, IIIST has contracted with experienced English as a Second Language instructors in China to deliver ESL programs to students at IIIST. Some contract ESL instruction was also provided by PSU ESL specialists over the summer months. It is clear that ongoing attention to English instruction at IIIST will be very important as the program moves forward.

\section{Communication}

Many academic and administrative issues have arisen in the program which have needed to be resolved. Language issues, as well as differences in culture and education systems sometimes cause problems in discussions and problem resolution. The good faith efforts of both sides, regular visits, and ongoing consultation with a Chinese faculty member in the ECE department at PSU have been important in overcoming these communication challenges.

IIIST and PSU require that the PSU faculty and Chinese faculty mentors communicate during the course sessions, consulting about teaching requirements, syllabi, assignments, and examinations and grading. This communication typically takes place by email.

To date, some PSU faculty members have visited IIIST to meet with the Chinese faculty mentors to discuss course instruction and other issues. Some PSU faculty have also given lectures to the IIIST students so that the students in China can experience face to face the style of instruction at PSU. PSU administrators have also visited IIIST to meet their Chinese counterparts and resolve administrative policy issues. 
Admissions

Admission to PSU is scheduled to occur at the junior year, yet some students have applied to the university late, others have not yet passed TOEFL, and some have not yet passed all the required prerequisite courses, or achieved the grade point average required by PSU for transfer admission to the University. Consequently what was originally envisioned as a fairly straightforward 2-year transfer program has expanded to more courses per term than were originally planned, with some students taking longer to complete requirements than others. The admissions process for these international students can seem confusing to IIIST students, and the process consumes considerable staff time at PSU.

A formal transfer articulation agreement with Jiao Tong University for the courses transferring to PSU is under development at the time of the writing of this paper. Once completed, this agreement should smooth the admissions process to PSU for qualified students at IIIST.

\section{Administrative policies}

PSU and IIIST have worked to develop a common understanding of registration, academic standing, prerequisite, and other PSU administrative policies as they affect the PSU students at IIIST. Due to differences in the structure of educational programs in the two countries, policies commonly understood by American students and administrators have needed to be explained, and an appropriate implementation plan and schedule put into place at IIIST.

\section{$\underline{\text { Successes to date }}$}

\section{Student pass rate}

There are 53 students who have now completed four years study at IIIST. Among them, 33 students have been admitted by PSU. These students have passed all the courses required in the PSU program and have applied for graduation from PSU as of the writing of this paper. It is probable that the first PSU degrees from this program will be awarded in Spring, 2005.

\section{Applications for study at PSU}

More than $50 \%$ of the students who are studying at IIIST have expressed interest in continuing their studies at PSU. Due to current difficulties in getting student visas approved, only a few students have applied to study at the PSU campus to date. We anticipate that in the future more IIIST students will be successful in receiving visas and coming to PSU for graduate study, or for completion of their undergraduate degree on the PSU campus. 


\section{Placement}

Among the 53 students who have completed four years study at IIIST, 48 have been placed in their first professional positions. Of these, fourteen students work for American companies, four students work in a Taiwanese company, one student works in a Japanese company, one in an Indian company and one in Swedish company.

Interest by PSU students in travel to China

The program has generated strong interest from PSU students wishing to travel to China. One PSU student will be piloting a Study Abroad experience at IIIST during Spring/Summer 2005. A small group of PSU students will visit IIIST and china for cultural study and industrial internships for the first time in summer 2005.

\section{Summary}

Through this partnership in CS and ECE undergraduate education at IIIST, PSU hopes to develop additional education program opportunities in China, and to develop additional research collaborations. The program is already contributing to the internationalization of the PSU campus community in the participating departments. PSU faculty are communicating with colleagues in China, and discussions exploring research interests are beginning.

The PSU-IIIST partnership has attracted wide attention in China. Many Chinese students are interested in studying in the U.S. and realize they can now take American courses at IIIST and work towards a PSU degree. Some Taiwanese businessmen have recently indicated that they intend to send their children to IIIST.

Higher education opportunities in China have attracted universities in many foreign countries such as Australia, New Zealand, Canada, Britain, Singapore, Japan, etc. To date there are very few American universities operating programs in China, though many students wish to study at American schools. Consequently, there should be good opportunities for the future development of the PSU-IIIST program.

MARCIA FISCHER is Assistant Dean for Enrollment and Outreach at Portland State University's Maseeh College of Engineering and Computer Science. Previously she was Director of Academic Services at Oregon Graduate Institute of Science and Technology. She is an ASEE member, and active in student advising, academic policy, and international issues on campus.

JIM MORRIS is an IEEE Fellow and 22-year ASEE member, and has served as EE/ECE Department Chair at both SUNY-Binghamton and Portland State. His research interests lie in electronics packaging, and nanoelectronics/thin films. He is actively committed to the development of international work/study experiences for engineering students.

FU LI is Professor of Electrical and Computer Engineering at PSU. He is a senior member of IEEE, with research interests in the areas of digital signal/image processing, computer systems integration, and 
communication. He received his Ph.D. from the University of Rhode Island, and his M.S. degree is from Sichaun University in China.

CYNTHIA BROWN received her Ph.D. in mathematics from the University of Michigan. She has been chair of the Computer Science Department at Portland State since 1998 and was previously dean of the College of Computer Science at Northeastern University. Her research interests are in the analysis of algorithms and compiler front end design.

MALGORZATA CHRZANOWSKA-JESKE received her Ph.D. in electrical engineering from Auburn University. She held university and industry positions in Poland prior to joining Portland State. Currently she is Professor and Chair of PSU's Electrical and Computer Engineering Department. Her research interests include vertically-integrated CAD in VSLI ICs and MS-SOCs and nanotechnology.

AGNES HOFFMAN is Associate Vice Provost for Enrollment Management and Student Affairs at Portland State University.. She has responsibility for the areas of Admissions, Registrations and Records. She holds an MS in journalism from Northwestern University and an MBA from Portland State.

XIANGFU ZONG is founding president of the International Institute for Information Science and Technology in Shanghai, China. Professor Zong is also Director of the Microfabrication Institute at Shanghai JiaoTong University. For many years he was on the faculty at Fudan University, where he was most recently Dean of the Department of Materials Science. 